\title{
Factors associated with hypertension and its management among older rural Australians
}

\section{Authors}

Juliana M. Betts, MPH, School of Public Health and Preventive Medicine, Monash University, Melbourne, Victoria, Australia. Author contribution 30\%.

Caroline Gao, PhD, School of Public Health and Preventive Medicine, Monash University, Melbourne, Victoria, Australia. Author contribution 10\%.

David Brown, GradDip Ed. School of Public Health and Preventive Medicine, Monash University, Melbourne, Victoria, Australia. Author contribution 10\%.

Jillian Ikin, PhD, Hazelwood Health Study, School of Public Health and Preventive Medicine, Monash University, Melbourne, Victoria, Australia. Author contribution 10\%.

Roshan Maniam, MBBS Hons, Monash University, Malaysia. Author contribution 5\%.

Dion Stub, PhD, Department of Cardiology, Alfred Health, School of Public Health and Preventive Medicine, Monash University, Melbourne, Victoria, Australia. Author contribution $5 \%$.

Michael J. Abramson, PhD, School of Public Health and Preventive Medicine, Monash University, Melbourne, Victoria, Australia. Author contribution 15\%.

Danny Liew, PhD, School of Public Health and Preventive Medicine, Monash University, Melbourne, Victoria, Australia, danny.liew@monash.edu (corresponding author). Author contribution $15 \%$.

\section{Corresponding author}

Professor Danny Liew, School of Public Health and Preventive Medicine, Monash University, 553 St Kilda Rd, Melbourne, Victoria, 3004. T +6139903 0759 E danny.liew@monash.edu

\section{Disclosure}

This is the author manuscript accepted for publication and has undergone full peer review but has not been through the copyediting, typesetting, pagination and proofreading process, which may lead to differences between this version and the Version of Record. Please cite this article as doi: $10.1111 /$ AJR.12634

This article is protected by copyright. All rights reserved 
The Hazelwood Health Study is funded by the Victorian Department of Health \& Human Services. This paper presents the views of the authors and does not represent the views of the Department.

\section{Acknowledgements}

We would like to thank Andrea Taggert, Shantelle Allgood, Susan Denny, Sylvia Pomeroy, Melanie Reeves, Kylie Sawyer and Kristina Thomas for their assistance with recruitment and conducting the testing.

\section{Conflict of interest}

JB declares a traineeship supported by the Victorian Medical Specialist Training Program. DS holds an unrelated National Heart Foundation fellowship. MJA holds investigatorinitiated grants from Pfizer and Boehringer-Ingelheim for unrelated research. He has also undertaken an unrelated consultancy for Sanofi. DL has received research support and honoraria from Abbvie, Astellas, AstraZeneca, Bristol-Myers Squibb, Novartis, Pfizer, Sanofi and Shire for work unrelated to this study. Other authors have no potential competing interests to declare.

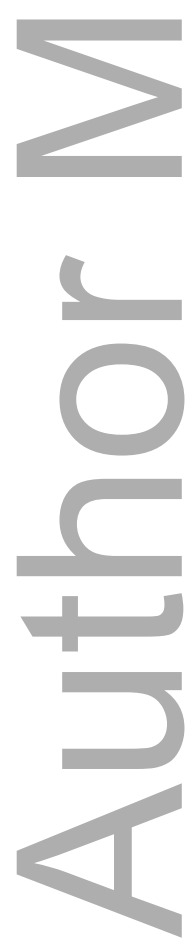




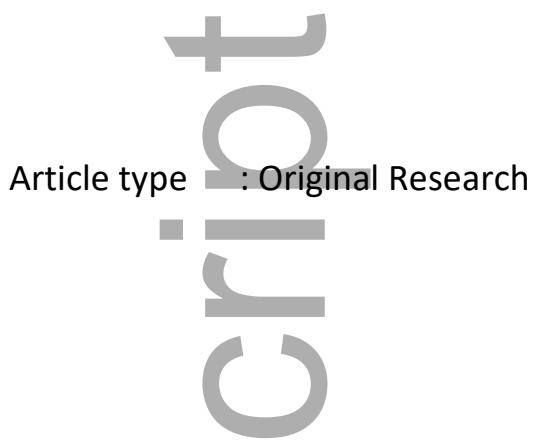

\title{
Factors associated with hypertension and its management among older rural Australians
}

\begin{abstract}
Objectives

Hypertension is aleading risk factor for death and disability. We aimed to estimate the prevalence of hypertension in an older rural Australian cohort and identify predictorsof hypertension management.
\end{abstract}

Design

Analysis of cross-sectional data collected from participants in a prospective cohort study.

Setting

The Victorian rural towns of Morwell and Sale in 2018-2019.

Participants

A weighted random sample of 1,119 eligible participants from Morwell or Sale, aged $\geq 55$ 90 years for males and $\geq 60-90$ years for females, was drawn from the Hazelwood Health Study Adult Survey cohort.

Main outcome measures

Blood pressure (BP), body mass index (BMI), left ventricular hypertrophy (LVH) by electrocardiogram, estimated glomerular filtration rate (eGFR) and glycoslylatedhaemoglobin 
$\left(\mathrm{HbA}_{1 \mathrm{c}}\right)$ were measured.Participants with hypertension were categorised as managed, undermanaged or unmanaged.

Results

Testing undertaken of498 participantsestimated the weightedprevalence of hypertension (defined as $\mathrm{BP} \geq 140 / 90 \mathrm{mmHg}$, a self-reported doctor-diagnosis of hypertension or taking antihypertensive medication)to be $79.9 \%$ (95\%CI: 75.7-83.4). Of those, 54.5\% (49.4-60.0) had managed hypertension $(<140 / 90 \mathrm{mmHg}), 37.1 \%$ (32.3-42.1) undermanaged hypertension and $8.4 \%$ (5.9-11.9) a new finding ofhypertension (unmanaged hypertension). Current employment (RR 1.47, 95\%CI: 1.06-2.02) and single marital status (RR 1.45,1.4-1.84) were associated with under- or unmanaged hypertension.Compared with no hypertension, the hypertensive groups were more likely demonstrate markers of end organ damage such as LVH and impaired renal function.

Conclusion

Hypertension is a highly prevalent condition among older rural Australianswhich is suboptimally identified and managed.

Abbreviations

$\mathrm{BP}=$ blood pressure; eGFR = estimated glomerular filtration rate; $\mathrm{HbA} 1_{\mathrm{c}}=$ glycoslylatedhaemoglobin

What is already known on this subject?

Rural Australians have a higher prevalence of hypertension and a higher risk of cardiovascular diseases, including death from ischaemic heart disease and stroke, compared to urban Australians. While treatment of hypertension is associated with a decrease in cardiovascular morbidty and mortality, the extent to which hypertension is optimally managed in rural settings was not well known.

\section{What this paper adds?}

Based on clinical testing, this study found hypertension in $80 \%$ of a sample of rural, older Australians. Almost half were not being managed to target. Participants with under- and 
unmanaged hypertension were more likely to have evidence of end organ damage. Among those with hypertension, being employed (as opposed to being retired or unemployed) was associated with an increased risk of having under- or unmanaged hypertension, whereas being married was associated with lower risk of under- or un managed hypertension.

\section{Introduction}

Rural-dwelling Australians havea higher prevalence of hypertension and a higher risk of cardiovasculardisease, such as mortality due to ischaemic heart disease and stroke, compared with urban-dwellers. ${ }^{1}$ This potentially reflects a range of factors, including a higher prevalence of obesity and risky alcohol consumption, an older population and limited access to health services in rural areas. ${ }^{1-3}$

More than ten years ago, as part of the Greater Green Triangle Risk Factor Study, Janus et al (2008) assessed the prevalence of hypertension among rural Australians in south-eastern Australia. ${ }^{4}$ They found that a third of participants had hypertension overall, increasing to 70$80 \%$ among those aged over 65 years. Furthermore, only $50 \%$ of participants with hypertension were being treated with medication and less than half (46.6\%, 95\%CI: 40.4 $52.9 \%$ ) of those on antihypertensive medication had their blood pressure (BP) controlled $(<140 / 90 \mathrm{mmHg})$.

Hypertension is multifactorial but contributed to bypreventable lifestyle factors such as diets high in salt and fat, physical inactivity, alcohol consumption and poorly managed psychological stress. ${ }^{5}$ The 2017-2018National Health Survey demonstrated an increase in the prevalence of obesity and experiences of psychological stress among Australian adults over the past decade, as well as low rates of physical activity and vegetable consumption. ${ }^{6}$ Moreover, since the analysis by Janus et al, several reviews have highlighted the significant reductions in cardiovascular morbidity and mortality from treating older adults with hypertension, which may have improvedmanagement over this period. ${ }^{7,8}$

Using data collected as part of a population health study in a sample of older rural Australians, we sought to describe the disease burden attributable to treated and untreated hypertension and identify predictorsof hypertension management.

\section{Methods}


Study design, setting and participants

This cross-sectional analysis used data collected for the Cardiovascular Stream of the Hazelwood Health Study, the aim of which was to study the health effects of exposure to emissions from the 2014 Hazelwood mine fire. ${ }^{9}$

A weighted random sample of 1,119 eligible participants was drawn from the Hazelwood Health Study's Adult Survey cohort, the methods for which have been published previously.

Participants were aged $\geq 55-90$ years for males and $\geq 60-90$ years for femaleswholived in, or within close proximity to, the Victorian rural towns of Morwell and Sale.

Participants who reported an underlying cardiovascular condition in the Adult Survey were oversampled to increase the probability of detecting cardiovascular events at follow-up, such that $50 \%$ met this criteria.

Data collection took place between October 2017 and May 2018.

Data sources

Three BP readings were taken using a digital automatic BP monitor (Omron, Matsusaka, Japan) with one minute rest between readings. The average of the last two measurements was used in the analysis.

Height and weight were measured and a questionnaire (see supplementary material) captured sociodemographic and health information.

Prescription medications taken over the past seven days were recorded, peripheral venous blood was collected (see supplementary material for laboratory processing methods) and a 12-lead electrocardiograph was obtained using a portable machine (Philips TC50, China).

Educational attainment, marital status and Index of Relative Socioeconomic Disadvantage (IRSD) scores ${ }^{11}$ were derived from participants' previous responses on the Adult Survey. ${ }^{10}$

Definitions

Hypertension was defined as a BP of $\geq 140 / 90 \mathrm{mmHg}$, a self-reported doctor-diagnosis of hypertension or use ofantihypertensive medications according to the Anatomical Therapeutic 
Chemical (ATC) classification (see supplementary material). ${ }^{12}$ The cut-off of $\geq 140 / 90 \mathrm{mmHg}$ was chosen to facilitate comparison with previous studies.

'Managed hypertension' was defined as a known diagnosis of hypertension and/or taking antihypertensive medication, with a measured BP < 140/90mmHg; 'undermanaged hypertension' was defined as a known diagnosis of hypertension and/or taking antihypertensive medication with a measured $\mathrm{BP} \geq 140 / 90 \mathrm{mmHg}$; and 'unmanaged hypertension' was defined as no known diagnosis of hypertension nor taking antihypertensive medication,buta measured $\mathrm{BP} \geq 140 / 90 \mathrm{mmHg}$.

Body mass index (BMI) was classified as 'underweight/normal' $<25 \mathrm{~kg} / \mathrm{m}^{2}$; 'overweight' 25 $30 \mathrm{~kg} / \mathrm{m}^{2}$; and 'obese' $\geq 30 \mathrm{~kg} / \mathrm{m}^{2}{ }^{13}$

History of cardiovascular disease implied the self-report of a medical diagnosis of atrial fibrillation, aneurysm, valvular disease, heart failure, myocardial infarction, coronary artery disease, stroke / transient ischaemic attack (TIA) or peripheral vascular disease.

Smoking status comprised'non-smoker' (not more than 100 cigarettes over entire lifetime), 'ex-smoker' (smoked more than 100 cigarettes, but did not currently smoke) or 'current smoker' (smoked over 100 cigarettes and continued to smoke on a regular basis).

An Alcohol Use Disorders Identification Test - Consumption (AUDIT-C)score of 0 indicateda 'non-drinker', 1-2 for females and 1-3 for males indicated'low risk' and $\geq 3$ for females or $\geq 4$ for males indicated 'high risk' alcohol consumption. ${ }^{14}$

Participants were considered physically active if over the previous 7 days, they reported having done any vigorous physical activity or at least 150 minutes of moderate physical activity. ${ }^{15}$

The presence of diabetes (type 1 or 2) was determined by self-reported doctor diagnosis, taking diabetes-associated medications (see supplementary material) or $\mathrm{HbA}_{1 \mathrm{c}} \geq 6.5 \%$. Left ventricular hypertrophy $(\mathrm{LVH})$ was deemed present if stated on the automatically generated ECG interpretative statement using an algorithm based upon the Cornell criteria. ${ }^{16}$

Renal impairment implied an estimated glomerular filtration rate (eGFR) of $<60 \mathrm{ml} / \mathrm{min} / 1.73 \mathrm{~m}^{2}$.

Data analyses 
Post-stratification weights ${ }^{17}$ were first obtained for the Adult Survey to correct for possible sampling bias.These were combined with over-sampling weights to correct for oversampling of participants with cardiovascular disease.The prevalences of managed, unmanaged and undermanaged hypertension were estimated using weighted proportions. Simple descriptive analyses examined the differences in participant characteristics in each group, utilising Pearson $\chi^{2}$ tests for categorical variablesand t-tests for continuous variables.

Log Poisson regression ${ }^{18}$ was used to estimate relative risks (RR) of having hypertension and un/undermanaged hypertension. Multiple imputation by chained equations (MICE) was usedfor missing data with 20 imputed datasets. All of the regression analyses accounted for weights, sampling stratification (Morwell versus Sale) and clustering at household level. Sensitivity analysis was conducted using unweighted and unimputed data.

Statistical analyses were undertaken using Stata version 15 (StataCorp, 2017, College Station, TX) and graphical displays were created using R version 3.4.4 (R Core Team 2008).

Ethics

Ethics approval was granted by the Monash University Human Research Ethics Committee (project number 1078).

\section{Results}

Figure 1 shows a flow diagram of participant recruitment.In total, 498 participants (recruitment rate $44.5 \%$ ) underwent clinical testing, of whom 405 were found to have hypertension. We estimated that the weighted prevalence of hypertension in this population was $79.9 \%$ (95\%CI 75.7-83.4).

Of the participants with hypertension, 226 (weighted 54.5\% [95\%CI 49.4-60.0]) had managed hypertension, 150 (weighted 37.1\%[32.3-42.1]) had undermanaged hypertension and 29 (weighted $8.5 \%$ [5.9-11.9]) had unmanaged hypertension.

Compared with no hypertension, the hypertensive groups tended to have higher proportions of older, single/divorced/widowed and retired participants (Table 1). They were also more likely to have a history of diabetes or cardiovascular disease,to be less physically activeand demonstrate markers of end organ damage such as LVH and impaired renal function(Table 2). 
The majority of participants with under- and unmanaged hypertension demonstrated isolated systolic hypertension (systolic $\mathrm{BP} \geq 140 \mathrm{mmHg}$ and diastolic $\mathrm{BP}<90 \mathrm{mmHg}$ ) (Figure 2). A few participants with managed hypertension had very low BP (Figure 2), implying overtreatment.

Among people taking antihypertensive medications, less than half (weighted $45 \%$ ) were taking a single agent, with angiotensin converting enzyme (ACE) inhibitors or angiotensin II receptor blockers being the most frequently used single agents (see supplementary material). There were no significant differences in antihypertensive regimens between managed or undermanaged hypertension groups.

Compared to those without hypertension, participants with any form of hypertension were more likely to be older (RR 1.05, 95\%CI 1.01-1.09, p=0.01), obese (RR 1.21, 1.05-1.40, p= 0.01 ), and have a history of cardiovascular disease (RR 1.17, 1.06-1.28, $\mathrm{p}=0.001)$ (Table 3). Being physically active protected against hypertension (RR 0.90, 0.81-0.99, $\mathrm{p}=0.03$ ).

Compared with managed hypertension, participants with under- or unmanaged hypertension were more likely to be employed, (RR1.47, 1.06-2.02, p=0.02) and be single/divorced/widowed (RR 1.45, 1.14-1.84, p=0.003). Having a history of cardiovascular disease was associated with a lower risk of having under- or unmanaged hypertension (RR $0.75,0.60-0.94, \mathrm{p}=0.01)$.

\section{Discussion}

The weighted prevalence of hypertension among our sample of rural, older Australians was high (80\%)but similar to that estimated by Janus et al approximately ten years prior in western Victoria. ${ }^{4}$ The most recent US guidelines define hypertension as a systolic BP $\geq 130 \mathrm{mmHg}$ or a diastolic BP $\geq 80 \mathrm{mmHg} .{ }^{19}$ Using this definition would have increased the proportion in our sample with hypertension, but this was not applied so as to facilitate comparison with previous studies and because current Australian guidelines maintain a cutoff $\geq 140 / 90 \mathrm{mmHg}$ in the general population. ${ }^{20}$

Amongthose with hypertension, almost half were not being managed to target (BP<140/90mmHg). While lower than the $76 \%$ observed byJanus et al, this level is still suboptimal, particularly considering that participants with under- and unmanaged hypertension were more likely to have evidence of LVH on ECG - a marker of end organ damageand independent risk factor for future cardiovascular events. ${ }^{4,21}$ 
Several barriers to the optimal management of hypertension among older adults have been identified, and tend to be system-, physician-and patient-related, such as uncertainty around the applicability of management guidelines for older persons and patient adherence to treatment for a largely asymptomatic condition. ${ }^{22}$ This is despite the fact that treatment of hypertension in the elderly has been associated with a decrease in cardiovascular morbidty and mortality. 8

Among those with hypertension, being employed (as opposed to being retired or unemployed) was associated with a $45 \%$ greater likelihood of having under- or unmanaged hypertension compared with managed hypertension, after controlling for knownconfounders. Workplaces are increasingly sedentary environments, and can be psychologically stressful-both factors associated with the development of hypertension and cardiovascular disease. ${ }^{23,24}$ Considering people spend the vast majority of their adult life at work, the workplace offers an ideal setting for health promotion programs targeting the primary prevention of cardiovascular risk factors.

Among those with hypertension, single, divorced, separated or widowed participants had a $47 \%$ higherrisk of under- or unmanaged hypertension compared tomarried participants. Marital status has previously been shown to impact BP, as well as other cardiovascular risk factors and cardiovascular events, with married persons generally demonstrating more favourable cardiovascular outcomes. ${ }^{25}$ This is possibly due to more social contact, less psychological stress, healthier meals and financial benefits. ${ }^{25}$

This study has many strengths. We were able to capture clinical information beyond merely the self-report of hypertension, including an objective measure of BP, possible confounding variables and clinical markers of end organ damage from prolonged hypertension. Our analysis addressed an important information gap in terms of quantification of the prevalence of hypertensionand its management among an older, rural cohort.

However, several limitations warrant mention. Participants were drawn from the Hazelwood Health Study Adult Survey, which averaged a 31\% recruitment rate. While weightings were applied to best reflect the source population, it remains possiblethat healthier and independent adults were possibly more likely to participate in the clinic-based assessments.Our study sample comprised predominantly Caucasians, which limited our ability to generalise the findings to the broader Australian population and to those from particular ethnic backgrounds, includingindigenous Australians. 
Not all factors associated with BP were able to be assessed and included in our analysis. Notably, dietary factors and other medical conditions could affectBP.Finally, history of hypertension and other conditions were based on self-report, and were not verified. It was uncertain if any information bias existed as a consequence and if it did, in what direction it took.

It is highly unlikely that the limitations of our study altereditsconclusion: that hypertension is common and not well managed in rural communities. A renewed focus should be placed on the primary prevention of hypertension and cardiovascular disease. Active monitoring for hypertension by medical practitioners is recommended, including frequent checks to ensure that treatment is adequate. Given workforce shortages and high demands on medical services, there is likely a role for practice nurses, pharmacists and automated devices at home.

\section{References}

1. Australian Institute of Health and Welfare. Australia's health 2016. Australia's health series no. 15. AUS 199. Canberra: AIHW; 2016.

2. Australian Bureau of Statistics. Population by Age and Sex, Regions of Australia, 2016. 2017. http://www.abs.gov.au/ausstats/abs@.nsf/0/151AA7593B394934CA2573210018DA4A?O peOpendocum [Accessed 18 June 2018].

3. Duckett S, Breadon P. Access all areas: new solutions for GP shortages in rural Australia, Grattan Institute, Melbourne. 2013. https://grattan.edu.au/wpcontent/uploads/2014/04/196-Access-All-Areas.pdf [Accessed 18 June 2018].

4. Janus ED, Bunker SJ, Kilkkinen A, et al. Prevalence, detection and drug treatment of hypertension in a rural Australian population: the Greater Green Triangle risk factor study 2004-2006. Internal Medicine Journal 2008; 38(12): 879-86.doi:10.1111/j.14455994.2007.01583.x.

5. World Health Organization. A global brief on hypertension; silent killer, global public health crisis. 2013. http://apps.who.int/iris/bitstream/10665/79059/1/WHO_DCO_WHD_2013.2_eng.pdf?ua= 1 [Accessed19 March 2018].

6. Australian Bureau of Statistics. National Health Survey: First Results, 2017-18. 2018. http://www.abs.gov.au/ausstats/abs@.nsf/mf/4364.0.55.001 [Accessed 2 January 2019]. 
7. Propsective Studies Collaboration. Age-specific relevance of usual blood pressure to vascular mortality: a meta-analysis of individual data for one million adults in 61 prospective studies. The Lancet 2002; 360(9349): 1903-13.

8. Musini, V., Tejani, A., Basset, K \& Wright, J. Pharmacotherapy for hypertension in the elderly. Cochrane Database of Systematic Reviews 2009. doi: 10.1002/14651858.CD000028.pub2

9. https://hazelwoodhealthstudy.org.au/

10. Ikin, J., Carroll, M., Walker, J., Borg, B., Brown, D., Cope, M., Del Monaco, A., Dennekamp, M., Dimitriadis, C., Gao, C., Guo, Y., Johnston, F., Liew, D., Maybery, D., Thompson, B., Sim, M\&Abramson M. Cohort Profile: The Hazelwood Health Study adult cohort. The International Journal of Epidemiology. In press.

11. Australian Bureau of Statistics. Census of Population and Housing: Socio-Economic Indexes for Areas (SEIFA), Australia, 2011. 2013. http://www.abs.gov.au/ausstats/abs@.nsf/Lookup/by\%20Subject/2033.0.55.001 2011 Ma in\%20Features IRSD 10005 [Accessed 19 June 2018].

12. WHO Collaborating Centre for Drug Statistics Methodology,Norwegian Institute of Public Health. ATC/DDD Index 2018. 2018. https://www.whocc.no/atc_ddd_index_and_guidelines/atc_ddd_index/[Acced 8 March 2018].

13. National Health and Medical Research Council. Clinical practice guidelines for the management of overweight and obesity in adults, adolescents and children in Australia. Melbourne: National Health and Medical Research Council; 2013.

14. Bush K, Kivlahan DR, McDonell MB, Fihn SD, Bradley KA. The AUDIT alcohol consumption questions (AUDIT-C): an effective brief screening test for problem drinking. Archives of Internal Medicine 1998; 158(16): 1789-95.

15. Department of Health. Australia's Physical Activity and Sedentary Behaviour Guidelines. 2017. http://www.health.gov.au/internet/main/publishing.nsf/content/health-pubhlthstrateg-phys-act-guidelines [26 June 2018].

16. Casale, P, Devereux, R, Kligfield, P, et al. Electrocardiographic detection of left ventricular hypertrophy: development and prospective validation of improved criteria. Journal of the American College of Cardiology 1985; 6(3): 572-580.

17. Gelman, A \& Carlin, J. Poststratification and weighting adjustments. In: Groves, R, Dillman, D, Eltinge, J, \& Litle, J, editors. Survey nonresponse. New York: Wiley; 2002. p. 289-302. 
18. Zou G. A modified poisson regression approach to prospective studies with binary data. American Journal of Epidemiology 2004; 159(7): 702-6.

19. Whelton PK, Carey RM, Aronow WS, et al. 2017 ACC/AHA/AAPA/ABC/ACPM/AGS/APhA/ASH/ASPC/NMA/PCNA Guideline for the Prevention, Detection, Evaluation, and Management of High Blood Pressure in Adults. Journal of the American College of Cardiology 2017: 24430.

20. National Heart Foundation of Australia. Guidelines for the diagnosis and management of hypertension in adults - 2016. Melbourne: National Heart Foundation of Australia; 2016.

21. Bombelli M, Facchetti R, Carugo S, et al. Left ventricular hypertrophy increases cardiovascular risk independently of in-office and out-of-office blood pressure values. Journal of Hypertension 2009; 27(12): 2458-64.

22. Alhawassi, T.M., Drass, I., \& Pont, L.G. Prevalence, prescribing and barriers to effective management of hypertension in older populations: a narrative review. Journal of pharmaceutical policy and practice 2015; 8(1): 24. doi: 10.1186/s40545-015-0042-6.

23. Healy, G., Lawler, S., Thorp, A., Neuhaus, M., Robson, E., Owen, N. \& Dunstan, D. Reducing prolonged sitting in the workplace (An evidence review: full report). Melbourne, Australia: Victorian Health Promotion Foundation; 2012.

24. LaMontagne, A.D.\& Keegal,T. Reducing stress in the workplace (An evidence review: full report). Melbourne, Australia: Victorian Health Promotion Foundation; 2012.

25. Manfredini R, De Giorgi A, Tiseo R, et al. Marital status, cardiovascular diseases, and cardiovascular risk factors: A review of the evidence. Journal of Women's Health 2017; 26(6): 624-32.

\section{Summary of Tables and Figures}

Table 1: Sociodemographic characteristics of participants according to hypertension classification.

Table 2: Clinical characteristics of participants according to hypertension classification.

Table 3: Relative risk of factors associated with hypertension vs no hypertension or un/undermanaged hypertension vs managed hypertension. 
Figure 1: Flow diagram of participant recruitment.

Figure 2: Scatter plot and frequency distributions for systolic and diastolic blood pressures by hypertension category.

\section{Tables}
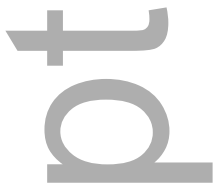

Table 1: Sociodemographic characteristics of participants according to hypertension classification

\begin{tabular}{|c|c|c|c|c|c|}
\hline Characteristic & $\begin{array}{c}\text { No } \\
\text { hypertension } \\
\mathrm{N}=93\end{array}$ & $\begin{array}{c}\text { Managed } \\
\text { hypertension } \\
\mathrm{N}=226\end{array}$ & $\begin{array}{c}\text { Undermanaged } \\
\text { hypertension } \\
\mathrm{N}=150\end{array}$ & $\begin{array}{c}\text { Unmanaged } \\
\text { hypertension } \\
\mathrm{N}=29\end{array}$ & p-value \\
\hline Age, weighted mean (SD) & $67.5(7.5)$ & $71.2(8.4)$ & $73.3(8.7)$ & $68.9(7.9)$ & $<0.001$ \\
\hline Age group & n (weighted \%) & $\mathrm{n}$ (weighted \%) & n (weighted \%) & n (weighted \%) & \\
\hline$<70$ & $56(64 \%)$ & $96(44 \%)$ & $54(37 \%)$ & $16(56 \%)$ & $<0.001$ \\
\hline$\geq 70$ and $<80$ & $31(29 \%)$ & $93(40 \%)$ & $58(34 \%)$ & $8(23 \%)$ & \\
\hline$\geq 80$ & $6(8 \%)$ & $37(16 \%)$ & $38(28 \%)$ & $5(21 \%)$ & \\
\hline \multicolumn{6}{|l|}{ Gender } \\
\hline Male & $53(61 \%)$ & $129(55 \%)$ & $81(52 \%)$ & $15(57 \%)$ & 0.674 \\
\hline \multicolumn{6}{|l|}{ Marital status } \\
\hline Married/de facto & $67(72 \%)$ & $155(69 \%)$ & $77(52 \%)$ & $17(56 \%)$ & 0.005 \\
\hline Single, divorced, separated or widowed & $26(28 \%)$ & $70(31 \%)$ & $73(48 \%)$ & $12(44 \%)$ & \\
\hline \multicolumn{6}{|l|}{ Ethnicity } \\
\hline Caucasian / White & $88(97 \%)$ & $221(98 \%)$ & $140(95 \%)$ & $28(96 \%)$ & 0.370 \\
\hline \multicolumn{6}{|l|}{ Employment status } \\
\hline Employed & $25(30 \%)$ & $29(15 \%)$ & $31(23 \%)$ & $6(20 \%)$ & 0.021 \\
\hline Retired & $57(58 \%)$ & $180(78 \%)$ & $114(74 \%)$ & $21(71 \%)$ & \\
\hline Other & $10(12 \%)$ & $16(7 \%)$ & $5(3 \%)$ & $2(9 \%)$ & \\
\hline \multicolumn{6}{|l|}{ Highest educational qualification } \\
\hline Secondary up to year 10 & $30(31 \%)$ & $89(39 \%)$ & $61(41 \%)$ & $11(35 \%)$ & 0.734 \\
\hline Secondary year $11-12$ & $22(23 \%)$ & $38(18 \%)$ & $21(13 \%)$ & $5(18 \%)$ & \\
\hline Certificate (trade/ apprenticeship/ technicians) & $26(31 \%)$ & $77(33 \%)$ & $49(34 \%)$ & $9(33 \%)$ & \\
\hline University or other Tertiary degree & $14(14 \%)$ & $21(10 \%)$ & $18(11 \%)$ & $4(14 \%)$ & \\
\hline IRSD, weighted mean (SD) & $897.8(80.6)$ & $887.9(98.4)$ & $883.8(101.9)$ & $854.8(104.4)$ & 0.338 \\
\hline
\end{tabular}

Table 2: Clinical characteristics of participants according to hypertension classification, $\mathrm{n}$ (weighted \%) 


\begin{tabular}{|c|c|c|c|c|c|}
\hline Characteristic & $\begin{array}{c}\text { No } \\
\text { hypertension }\end{array}$ & $\begin{array}{c}\text { Managed } \\
\text { hypertension }\end{array}$ & $\begin{array}{c}\text { Undermanaged } \\
\text { hypertension }\end{array}$ & $\begin{array}{l}\text { Unmanaged } \\
\text { hypertension }\end{array}$ & p-value \\
\hline Unweighted base & $\begin{array}{c}\mathrm{N}=93 \\
\text { n (weighted \%) }\end{array}$ & $\begin{array}{c}\mathrm{N}=226 \\
\text { n (weighted \%) }\end{array}$ & $\begin{array}{c}\mathrm{N}=150 \\
\text { n (weighted \%) }\end{array}$ & $\begin{array}{c}\mathrm{N}=29 \\
\mathbf{n} \text { (weighted \%) }\end{array}$ & \\
\hline History of cardiovascular diseases ${ }^{\dagger}$ & $24(23 \%)$ & $133(52 \%)$ & $83(49 \%)$ & $2(4 \%)$ & $<0.001$ \\
\hline Diabetes & $10(10 \%)$ & $65(27 \%)$ & $35(22 \%)$ & $3(12 \%)$ & 0.008 \\
\hline \multicolumn{6}{|l|}{ Smoking status } \\
\hline Non-smoker & $53(55 \%)$ & $105(47 \%)$ & $71(48 \%)$ & $14(48 \%)$ & 0.654 \\
\hline Ex-smoker & $33(37 \%)$ & $103(45 \%)$ & $71(47 \%)$ & $12(41 \%)$ & \\
\hline Current smoker & $7(9 \%)$ & $18(8 \%)$ & $8(5 \%)$ & $3(12 \%)$ & \\
\hline \multicolumn{6}{|l|}{ Alcohol consumption } \\
\hline Non-drinker & $23(23 \%)$ & $52(23 \%)$ & $44(28 \%)$ & $5(19 \%)$ & 0.883 \\
\hline Low risk & $31(34 \%)$ & $85(36 \%)$ & $47(31 \%)$ & $12(41 \%)$ & \\
\hline High risk & $38(43 \%)$ & $89(41 \%)$ & $59(40 \%)$ & $12(40 \%)$ & \\
\hline Physically active & $62(67 \%)$ & $106(48 \%)$ & $65(42 \%)$ & $15(48 \%)$ & 0.004 \\
\hline \multicolumn{6}{|l|}{ BMI } \\
\hline Underweight/Normal(BMI $<2$ & $28(29 \%)$ & $32(14 \%)$ & $30(21 \%)$ & $6(19 \%)$ & 0.068 \\
\hline Overweight $\left(25 \leq \mathrm{BMI}<30 \mathrm{~kg} / \mathrm{m}^{2}\right)$ & $33(37 \%)$ & $74(34 \%)$ & $50(33 \%)$ & $12(40 \%)$ & \\
\hline Obese $\left(\mathrm{BMI} \geq 30 \mathrm{~kg} / \mathrm{m}^{2}\right)$ & $32(34 \%)$ & $120(51 \%)$ & $70(46 \%)$ & $11(41 \%)$ & \\
\hline LVH on ECG & $3(3 \%)$ & $25(12 \%)$ & $24(17 \%)$ & $7(24 \%)$ & 0.004 \\
\hline Renal impairment $^{\ddagger}$ & $3(3 \%)$ & $48(21 \%)$ & $30(21 \%)$ & $1(3 \%)$ & $<0.001$ \\
\hline
\end{tabular}

†Self-reported doctor diagnosis of hypercholesterolemia, atrial fibrillation, aneurysm, valvular disease, heart failure, myocardial infarction, coronary artery disease, stroke / TIA and/or peripheral vascular disease.

eGFR $<60 \mathrm{ml} / \mathrm{min} / 1.73 \mathrm{~m}$

BMI= Body Mass Index; LVH= left ventricular hypertrophy; EGC=electrocardiogram; eGFR = estimated glomerular filtration rate

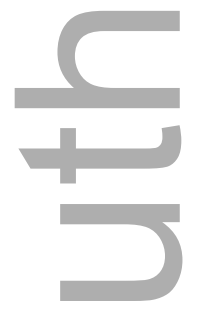

Table 3: Relative riskof factors associated with hypertension vs no hypertension or un-/undermanaged hypertension vs managed hypertension.

\begin{tabular}{|c|c|c|c|c|c|c|}
\hline & \multicolumn{3}{|c|}{ Hypertension vs No hypertension } & \multicolumn{3}{|c|}{$\begin{array}{l}\text { Un-/undermanaged hypertension } \\
\text { vs managed hypertension }\end{array}$} \\
\hline & $\mathrm{RR}$ & $95 \% \mathrm{CI}$ & p-value & $\mathrm{RR}$ & $95 \%$ CI & p-value \\
\hline Age ( per 5 years) & 1.05 & $1.01,1.09$ & 0.010 & 1.07 & $0.98,1.17$ & 0.113 \\
\hline
\end{tabular}




\begin{tabular}{|c|c|c|c|c|c|c|}
\hline Males & 0.96 & $0.87,1.06$ & 0.384 & 1.13 & $0.90,1.43$ & 0.294 \\
\hline Single, divorced, separated or widowed & 1.05 & $0.95,1.15$ & 0.367 & 1.45 & $1.14,1.84$ & 0.003 \\
\hline Employed & 1.01 & $0.86,1.19$ & 0.865 & 1.47 & $1.06,2.02$ & 0.020 \\
\hline \multicolumn{7}{|l|}{ Highest educational qualification } \\
\hline Secondary up to year 10 & Ref & & & Ref & & \\
\hline Secondary year $11-12$ & 0.97 & $0.84,1.12$ & 0.664 & 0.81 & $0.56,1.18$ & 0.278 \\
\hline Certificate (trade/ apprenticeship/technicians) & 1.05 & $0.95,1.17$ & 0.343 & 1.01 & $0.78,1.32$ & 0.916 \\
\hline tiary Institute degree & 1.03 & $0.87,1.22$ & 0.716 & 0.95 & $0.67,1.35$ & 0.762 \\
\hline \multicolumn{7}{|l|}{ BMI } \\
\hline Underweight/Normal(BMI<25kg/m²) & Ref & - & - & Ref & - & - \\
\hline Overweight $(25 \leq \mathrm{BMI}$ & 1.13 & $0.98,1.32$ & 0.102 & 0.79 & $0.58,1.07$ & 0.132 \\
\hline Obese $(\mathrm{BMI} \geq 3$ & 1.21 & $1.05,1.40$ & 0.011 & 0.78 & $0.59,1.02$ & 0.072 \\
\hline \multicolumn{7}{|l|}{ Smoking status } \\
\hline Non-smoker & Ref & - & - & Ref & - & - \\
\hline Ex-smoker & 1.08 & $0.97,1.21$ & 0.138 & 1.02 & $0.79,1.32$ & 0.860 \\
\hline Current smoker & 1.07 & $0.85,1.34$ & 0.570 & 0.83 & $0.47,1.46$ & 0.520 \\
\hline \multicolumn{7}{|l|}{ Alcohol consumption } \\
\hline Non-drinker & Ref & - & - & Ref & - & - \\
\hline Low risk & 1.01 & $0.89,1.13$ & 0.902 & 0.90 & $0.68,1.19$ & 0.461 \\
\hline High risk & 1.04 & $0.92,1.19$ & 0.526 & 0.89 & $0.65,1.21$ & 0.448 \\
\hline Physically active & 0.90 & $0.81,0.99$ & 0.031 & 0.88 & $0.69,1.10$ & 0.260 \\
\hline History of cardiovascular diseases ${ }^{\dagger}$ & 1.17 & $1.06,1.28$ & 0.001 & 0.75 & $0.60,0.94$ & 0.014 \\
\hline Diabetes & 1.08 & $0.99,1.18$ & 0.086 & 0.79 & $0.59,1.06$ & 0.119 \\
\hline IRSD ( per 100 score) & 1.00 & $0.96,1.05$ & 0.932 & 0.93 & $0.84,1.03$ & 0.183 \\
\hline
\end{tabular}

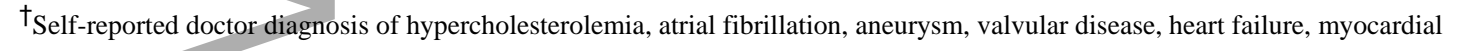
infarction, coronary artery disease, stroke / TIA and/or peripheral vascular disease. $\mathrm{BMI}=$ Body Mass Index; IRSD = Index of Relative Socioeconomic Disadvantage

\section{Figures}
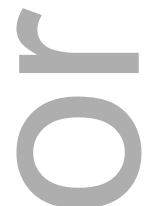

Figure 1: Flow diagram of participant recruitment

Figure 2: Scatter plot and frequency distributions for systolic and diastolic blood pressures by hypertension category 
4,056 participants completed the Adult Survey (May 2016- February 2017) (Morwell n= 3,096; Sale $n=960$ )
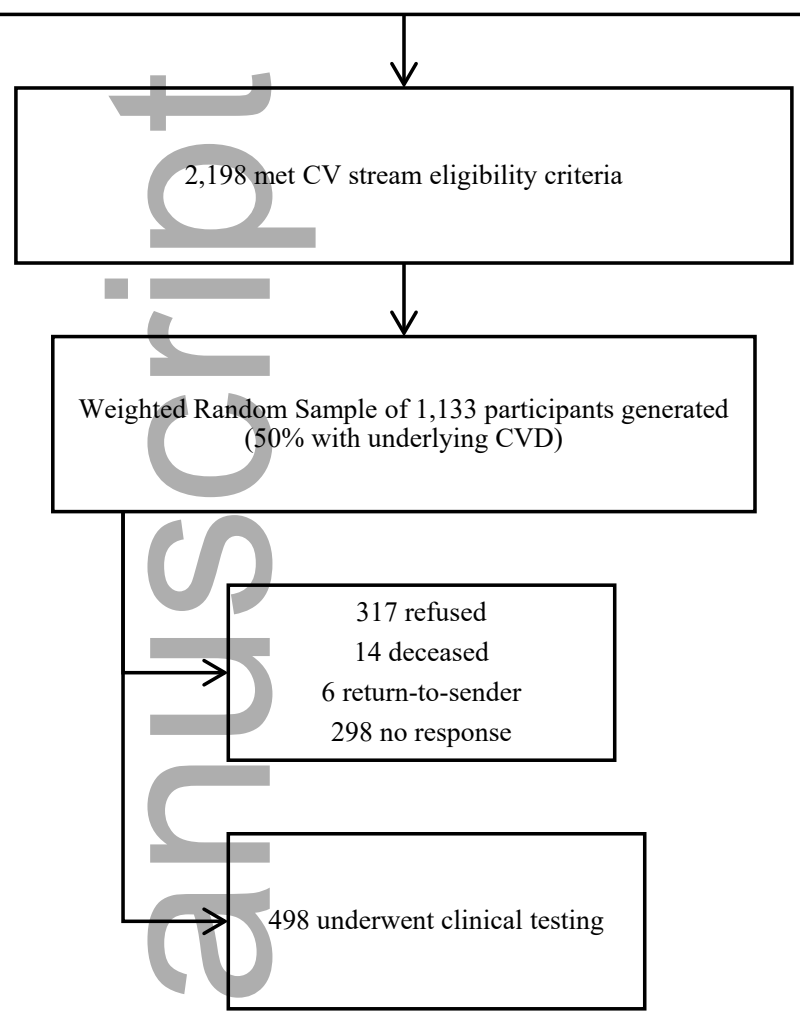

Figure 1: Flow diagram of participant recruitment






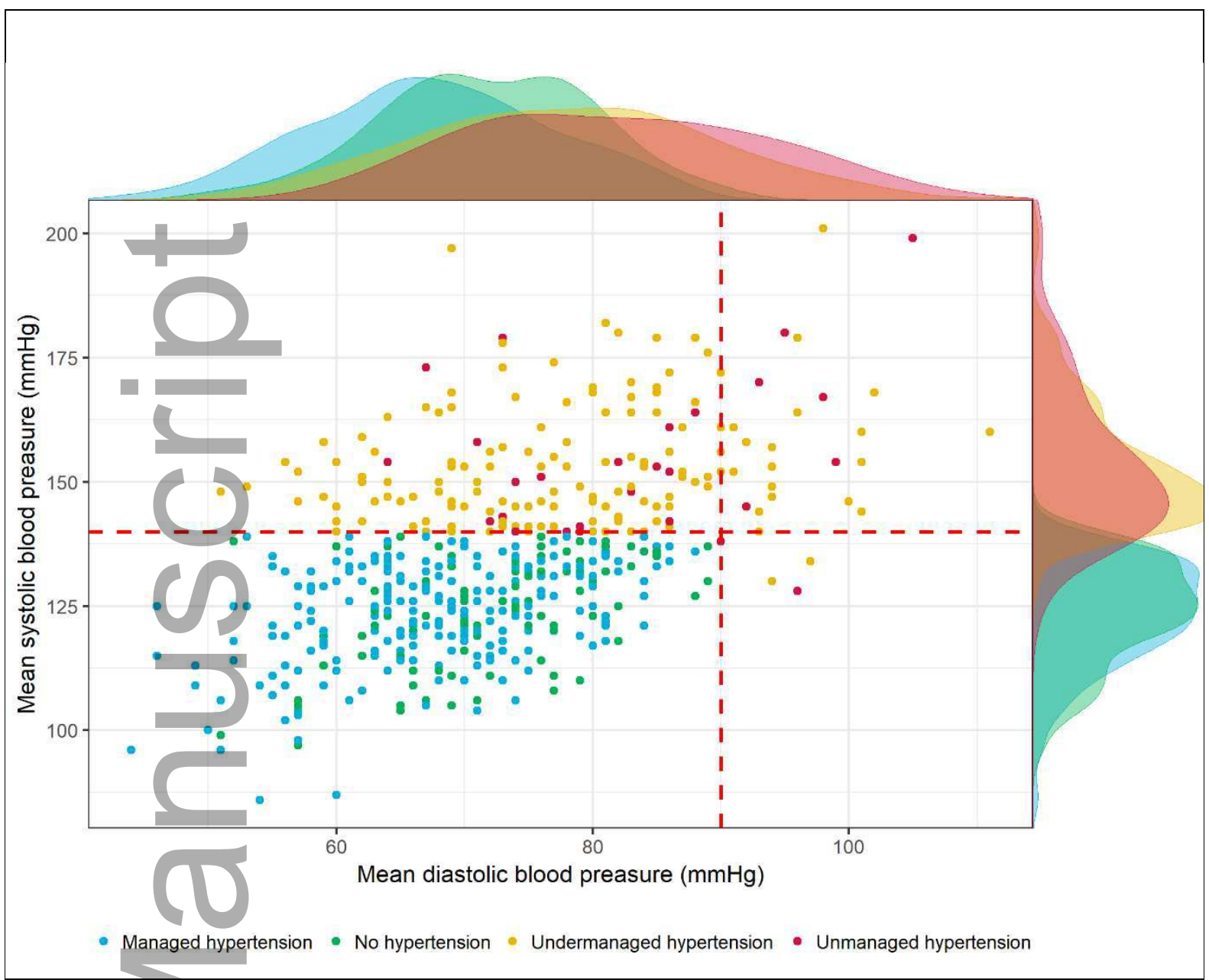

Figure 2: Scatter plot and frequency distributions for systolic and diastolic blood pressures by hypertension category.






\section{University Library}

\section{- M M N E R VA A gateway to Melbourne's research publications}

Minerva Access is the Institutional Repository of The University of Melbourne

Author/s:

Betts, JM;Gao, C;Brown, D;Ikin, J;Maniam, R;Stub, D;Abramson, MJ;Liew, D

Title:

Factors associated with hypertension and its management among older rural Australians

Date:

2020-05-28

Citation:

Betts, J. M., Gao, C., Brown, D., Ikin, J., Maniam, R., Stub, D., Abramson, M. J. \& Liew, D. (2020). Factors associated with hypertension and its management among older rural Australians. AUSTRALIAN JOURNAL OF RURAL HEALTH, 28 (4), pp.399-407. https:// doi.org/10.1111/ajr.12634.

Persistent Link:

http://hdl.handle.net/11343/275790 